\title{
Epoxy/BN Micro- and Submicro-composites: Dielectric and Thermal Properties of Enhanced Materials for High Voltage Insulation Systems
}

\author{
Thomas Heid \\ École de Technologie Supérieure (ETS) \\ 1100 Notre-Dame Street West, Montreal, QC, H3C 1K3 Canada \\ Michel Fréchette \\ Institut de Recherche d'Hydro-Québec (IREQ) \\ 1800 Lionel-Boulet Blvd., Varennes, QC, J3X 1S1, Canada \\ and Eric David \\ École de Technologie Supérieure (ETS) \\ 1100 Notre-Dame Street West, Montreal, QC, H3C 1K3 Canada
}

\begin{abstract}
Hexagonal boron nitride (h-BN) is a very promising material for application in high voltage insulation engineering due to its high thermal conductivity and good electrical insulating properties. In order to study the effect of incorporating BN particles in epoxy resin, composites with different filler sizes and several $\mathrm{BN}$ loadings have been fabricated. Two different filler sizes, one micrometric with an average grain size of $9 \mu \mathrm{m}$ and a submicrometric one with $0.5 \mu \mathrm{m}$, have been used to form composites. The amount of either type of $\mathrm{BN}$ in the matrix has been varied from 1 to $5 \mathrm{wt} \%$. Dielectric and thermal performances of the test specimens have been assessed by means of Dielectric Spectroscopy, Differential Scanning Calorimetry, surface erosion, AC breakdown tests and thermal conductivity measurements. It has been found that incorporation of BN particles in the epoxy resin resulted in significant improvements of parameters such as resistance to electrical discharge, as well as diminished dielectric losses for the composites at higher temperatures. Furthermore, BN composites with $5 \mathrm{wt} \%$ filler loadings have shown a noteworthy enhancement of thermal conductivities, which was more distinct for the submicrometric BN composite.
\end{abstract}

Index Terms - AC breakdown strength, boron nitride, dielectric spectroscopy, epoxy, electrical discharge, polymer composites, surface erosion, thermal conductivity.

\section{INTRODUCTION}

EPOXY resins are commonly used dielectric materials for power applications such as spacers, cable terminations and machine insulation. Naturally such dielectrics are exposed to high electric, thermal and mechanical stresses during operation. Due to the technical development towards higher electrical field strengths and frequently concomitant increased thermal loads, improved materials are needed to meet those demands. Boron nitride (BN) is a very promising material for dielectric composites due to its high thermal conductivity, excellent mechanical features as well as for its electrical insulating properties [1, 2].

Recent studies have shown an improved thermal conductivity of composites after incorporating $\mathrm{BN}$ in an epoxy matrix [3-6], with a trend of superior performances by reducing filler sizes in non percolating networks $[4,7]$. Partially very high BN particle loadings of $20 \mathrm{wt} \%$ [4] and up to $90 \mathrm{wt} \%[5,6,8]$ in epoxy resins have been studied.

It has also been shown in the literature that dielectric breakdown strength could be slightly improved with nanometric filler sizes [9] whereas incorporation of submicrometric and micrometric particles in epoxy resin resulted in similar breakdown strengths compared to the neat epoxy at BN loadings of $10 \mathrm{wt} \%[7,9]$.

In this work, we aimed to affect the morphology of epoxy resin composites by adding either submicrometric or micrometric BN particles in comparatively low weight percentages $(\leq 5 \mathrm{wt} \%$ ) and verify the effects on dielectric and thermal performances of the resulting composites. 


\section{MATERIALS AND SAMPLE PREPARATION}

DER332 epoxy resin (DOW Chemicals) and Jeffamine D230 (Huntsman Corp.) curing agent were mixed in a ratio of 1000:344 parts. As filler materials, hexagonal boron nitride (h-BN) particles (Henze Boron Nitride Products AG) with two different average particle sizes, BN205 with average dimensions of $500 \mathrm{~nm}$, or BN600, which were of $9 \mu \mathrm{m}$ average size, were used to fabricate the composites (see Table 1 for details).

The filler particles were dispersed in the epoxy using manual stirring, followed by extensive mixing with a high energetic ultrasonic probe, to generate a homogeneous dispersion of the particles within the matrix. The resulting mixture and the curing agent were degassed separately, before subsequently adding the hardener to that mixture and dispersing it using a magnetic stir. After the final mixing procedure, the liquid composite was degassed again, cast into a stainless steel mold and cured for six hours at $100^{\circ} \mathrm{C}$, followed by a gradient cool down to ambient temperature. A release agent (QZ13) was applied on the mold before casting the epoxy, to facilitate removing the samples after the curing process. The samples were post-cured subsequently under vacuum for 48 hours at $140{ }^{\circ} \mathrm{C}$.

Composites with loadings of 1,2 and $5 \%$ per weight for either filler type were produced. The nomenclature for the resulting composites, consisting of epoxy and BN particles, will be referred to as e.g. BN205 1wt\% for epoxy with $1 \mathrm{wt} \%$ of BN205 throughout this work.

Table 1. Specifications for BN filler particles as provided by supplier.

\begin{tabular}{c|c|c|c}
\hline Filler type & $\begin{array}{c}\text { Particle size } \\
\text { in } \mu \mathrm{m}\end{array}$ & $\begin{array}{c}\text { Specific } \\
\text { surface area } \\
\text { in } \mathrm{m}^{2} / \mathrm{g}\end{array}$ & $\begin{array}{c}\text { Bulk } \\
\text { Density in } \\
\mathrm{g} / \mathrm{cm}^{3}\end{array}$ \\
\hline BN205 & 0.5 & $16-26$ & 0.2 \\
BN600 & 9 & $35-40$ & 0.5 \\
\hline
\end{tabular}

\section{EXPERIMENTAL METHODS}

\subsection{MICROSTRUCTURE ANALYSIS}

Samples were prepared by cutting with a diamond knife in a microtome (Leica RM2265) while being cooled to $-80{ }^{\circ} \mathrm{C}$ inside a nitrogen chamber. Subsequently they were sputtered with a $2 \mathrm{~nm}$ Platinum layer to prevent charging, before the samples were observed with a Hitachi S-3600N Scanning Electron Microscope (SEM).

\subsection{DIFFERENTIAL SCANNING CALORIMETRY}

Glass transition temperatures were measured by Differential Scanning Calorimetry (DSC) with a heat flow calorimeter (Q20, TA Instruments) on samples not exposed to the thermal post-treatment. Each sample was subjected to two thermal cycles with a heating rate of $10^{\circ} \mathrm{C} / \mathrm{min}$ from 20 to $250^{\circ} \mathrm{C}$, followed by a gradual cool down to $20^{\circ} \mathrm{C}$ at $10^{\circ} \mathrm{C} / \mathrm{min}$. The glass transition temperatures $\mathrm{T}_{\mathrm{g}}$ were obtained from the second cycle to ensure no thermal history of the samples.

\subsection{DIELECTRIC SPECTROSCOPY}

The frequency and temperature dependent dielectric response of the samples was obtained by Broadband Dielectric Spectroscopy (BDS, Novocontrol) for temperatures ranging from $-100^{\circ} \mathrm{C}$ to $+180^{\circ} \mathrm{C}\left( \pm 0.1^{\circ} \mathrm{C}\right)$, in isothermal steps of $5{ }^{\circ} \mathrm{C}$, for either low or high excitation voltages. Low excitation voltages of $3 \mathrm{~V}$ with a frequency range of $0.1 \mathrm{~Hz}$ to $1 \mathrm{MHz}$ were applied on one series of samples, whereas for high excitation voltages of $500 \mathrm{~V}$ the dielectric response was analyzed for frequencies from $0.1 \mathrm{~Hz}$ to $10 \mathrm{kHz}$ for the second sample series.

BDS measurements were performed on samples with $20 \mathrm{~mm}$ diameter on a parallel plate electrode setup, on samples with average thickness of $275 \mu \mathrm{m} \pm 5 \%$. The complex permittivity $\varepsilon^{*}$ as given in (1) was retrieved, with the real permittivity $\varepsilon^{\prime}$ representing the storage part and $\varepsilon^{\prime \prime}$ as imaginary or dielectric loss part.

$$
\varepsilon^{*}(f, T)=\varepsilon^{\prime}(f, T)-j \varepsilon^{\prime \prime}(f, T)
$$

\subsection{AC BREAKDOWN STRENGTH}

The dielectric breakdown strength was measured based on ASTM D 149 standard [10]. Samples were immersed in transformer oil (Luminol TR-i) and placed between two symmetrical ball tip electrodes with a diameter of $4 \mathrm{~mm}$. The short term test was used, where a $60 \mathrm{~Hz}$ voltage with a ramp rate of $2 \mathrm{kV} / \mathrm{s}$ was applied between the electrodes until the breakdown occurred. On each sample type 16 breakdowns were conducted, after which the ball tips have been replaced by new ones to avoid pitting.

\subsection{RESISTANCE TO ELECTRICAL DISCHARGE}

To evaluate the resistance to electrical discharges, each sample was exposed to partial discharges (PD) using a pointto-plane geometry which was operated in open air. A sinusoidal voltage of $4 \mathrm{kV}_{\mathrm{RMS}}$ at an enhanced frequency of $300 \mathrm{~Hz}$, to accelerate the ageing effect, was applied to the high voltage rod electrode, bearing a titanium ball tip with $4 \mathrm{~mm}$ in diameter. The samples were placed centrically on a ground electrode framed by an acrylic base plate, with the tip of the rod electrode facing the sample surface, separated by an air gap of $200 \mu \mathrm{m}$ (see Figure 1). Samples were exposed to the electrical discharges for 30 hours, equaling 150 hours of $60 \mathrm{~Hz}$ and 180 hours of $50 \mathrm{~Hz}$ equivalent time respectively.

The resistance to erosion due to electrical discharge was further evaluated by the use of a mechanical profilometer, based on the eroded volume that has been calculated from the attained data. The values of eroded sample volume can thus be seen as an inverse reference value of the resistance to partial discharge. Before passing the samples in the profilometer they were carefully cleaned in an ultrasonic bath, to remove the debris caused by the PD. 


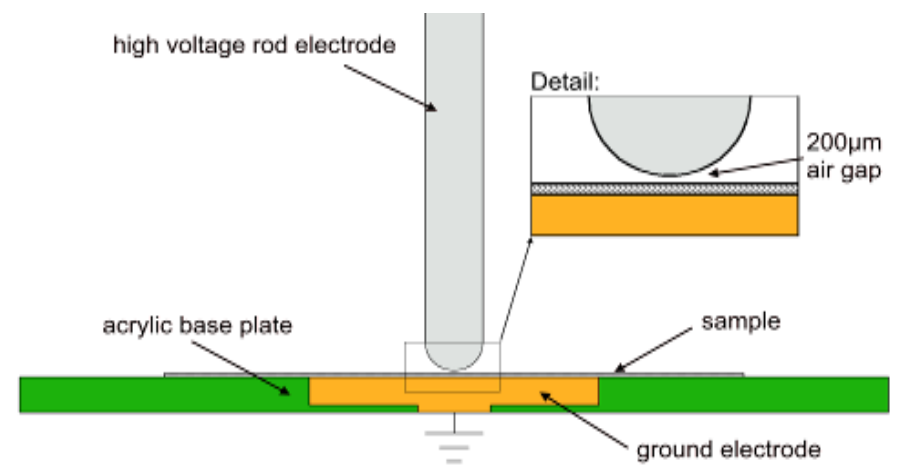

Figure 1. Schematic of surface erosion setup.

\subsection{THERMAL CONDUCTIVITY}

The thermal conductivity was obtained with a DTC-25 guarded heat flow meter (TA Instruments) in accordance with ASTM E 1530 standard [11]. Samples with 50.8 mm (2 inch) diameter were subsequently placed between an upper heating plate and a lower cooling plate of the device. A pressure of 15 psi applied on the upper plate assured an intimate contact between the sample, the heating and the cooling plate. The upper plate was heated, whereas the lower one was cooled, creating a $\Delta \mathrm{T}$ over the sample with thickness $\mathrm{t}$ and surface $\mathrm{A}$, leading to a medium sample temperature of $25^{\circ} \mathrm{C}$. The samples have been allowed for thermal stabilization, which occurred within one hour, in the measuring chamber. A heat flux transducer in the lower plate measures the heat flow $\mathrm{Q}$
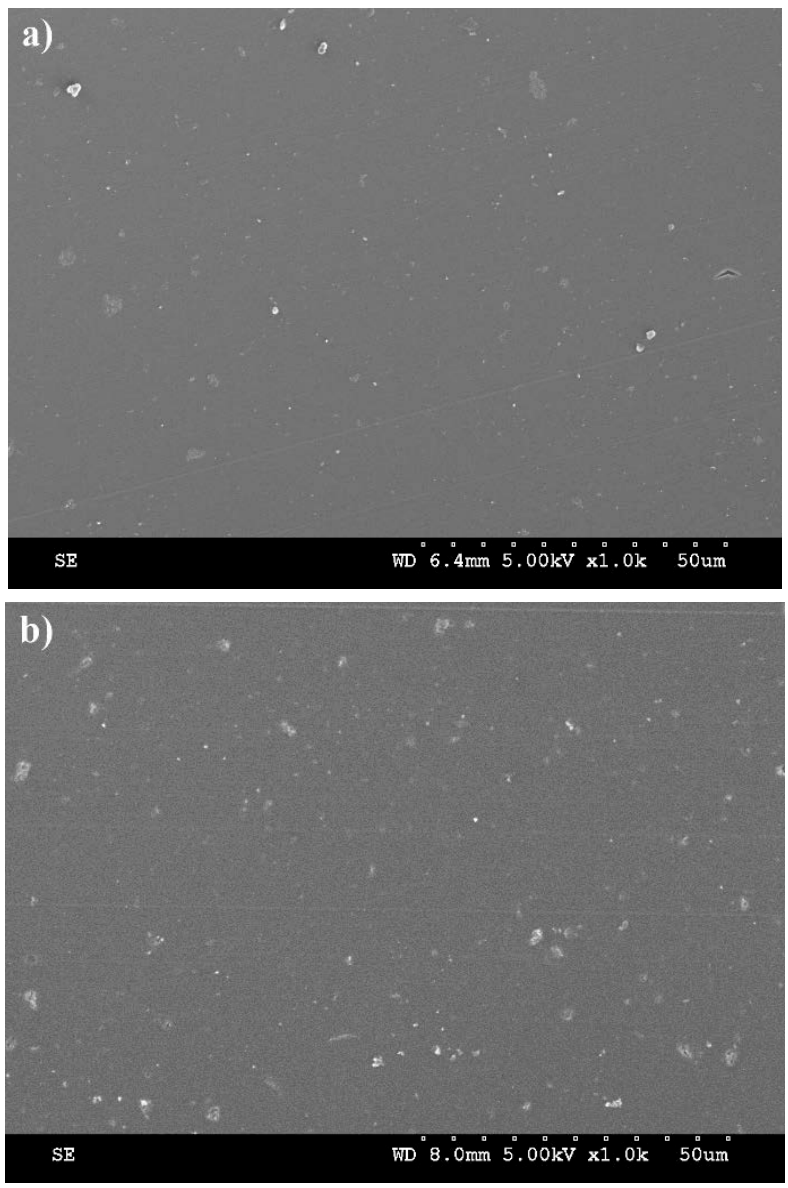

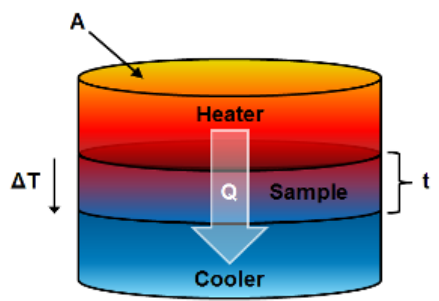

Figure 2. Schematic of heat flow meter setup.

through the sample, with which the thermal conductivity $\lambda$ can be expressed by equation (2):

$$
\lambda=\frac{Q / A}{\Delta T / t}
$$

\section{EXPERIMENTAL RESULTS AND DISCUSSION}

\subsection{MICROSTRUCTURE ANALYSIS}

In Figure 3 the SEM micrographs of the epoxy/BN composites are displayed. The left column (Figure 3a to 3c) represents the BN205 composites with increasing filler amount, whereas the right column (Figures $3 \mathrm{~d}$ to $3 \mathrm{f}$ ) represents the BN600 types. The dispersion of BN particles in the epoxy matrix has been qualitatively assessed by eye based on the SEM observations. The particles were found to be evenly dispersed throughout the composite volumes.
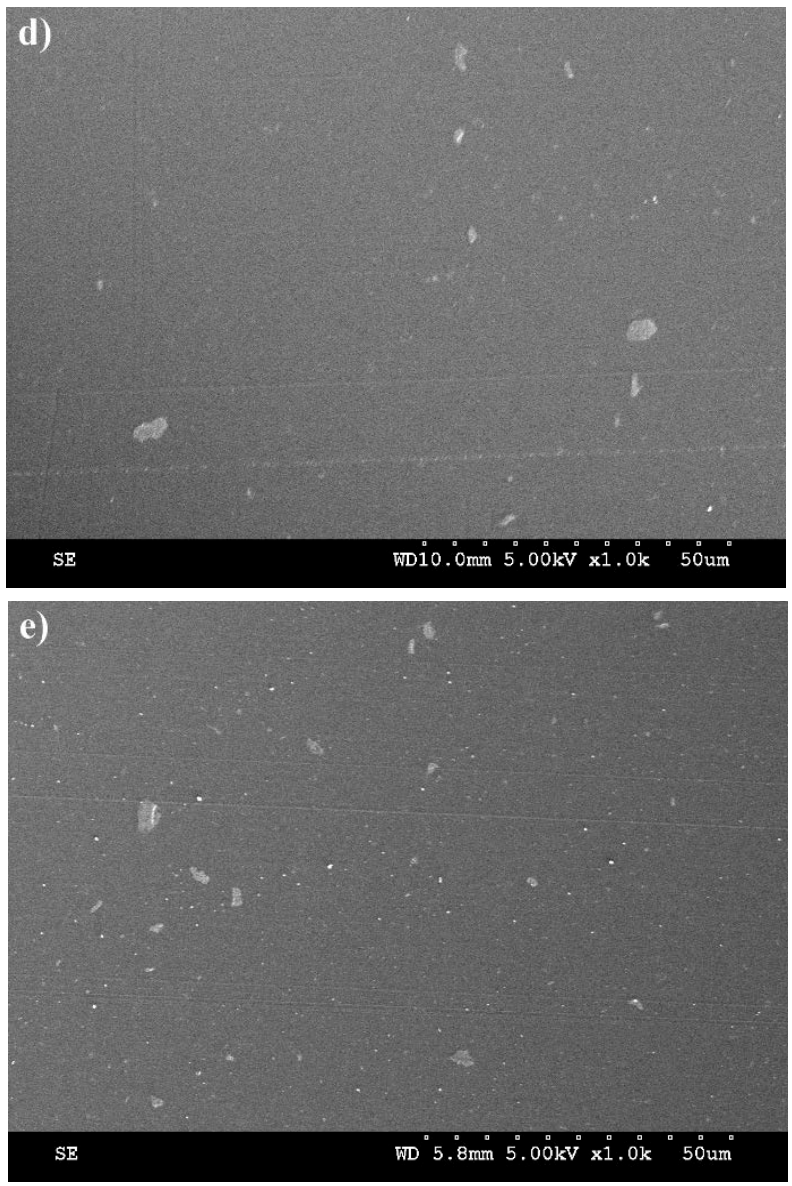

Figure 3. SEM micrographs of epoxy/BN composites a) BN205 1wt\%, b) BN205 2wt\%, c) BN205 5wt\%, d) BN600 1wt\%, e) BN600 2wt\%, f) BN600 5wt\%. 


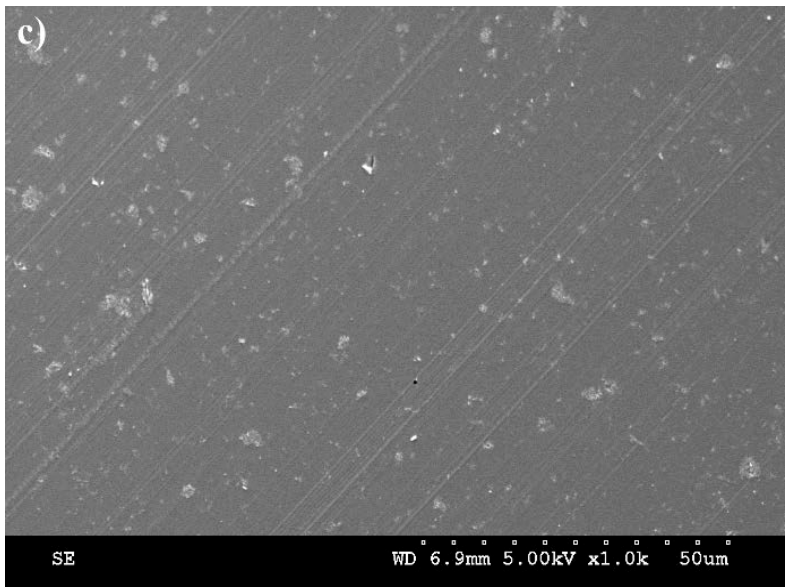

Figure 3. (Continued)

For the submicrometric BN205 composites some agglomerations could be seen though, especially with increasing amount of filler. Those agglomerations had dimensions of only a few microns in size, being below the $9 \mu \mathrm{m}$ average size of the micrometric filler particles.

\subsection{DIFFERENTIAL SCANNING CALORIMETRY}

In Figure 4 the DSC graphs from the second thermal cycle for all samples are presented. The derived glass transition temperatures $T_{g}$ are displayed in Table 2 . It was found that the addition of boron nitride into the epoxy matrix would slightly increase the glass transition temperature. The composites with $5 \mathrm{wt} \%$ of either submicrometric or micrometric BN type have exposed the highest $\mathrm{T}_{\mathrm{g}}$ values of approximately $96^{\circ} \mathrm{C}$ and $95^{\circ} \mathrm{C}$ respectively. The glass transition phenomenon is linked to the movement of the main chains within the epoxy network, therefore it can be derived that the incorporation of $\mathrm{BN}$ particles in the epoxy matrix slightly reduces the mobility of the epoxy chains, subsequently leading to the minor increase in $\mathrm{T}_{\mathrm{g}}$.

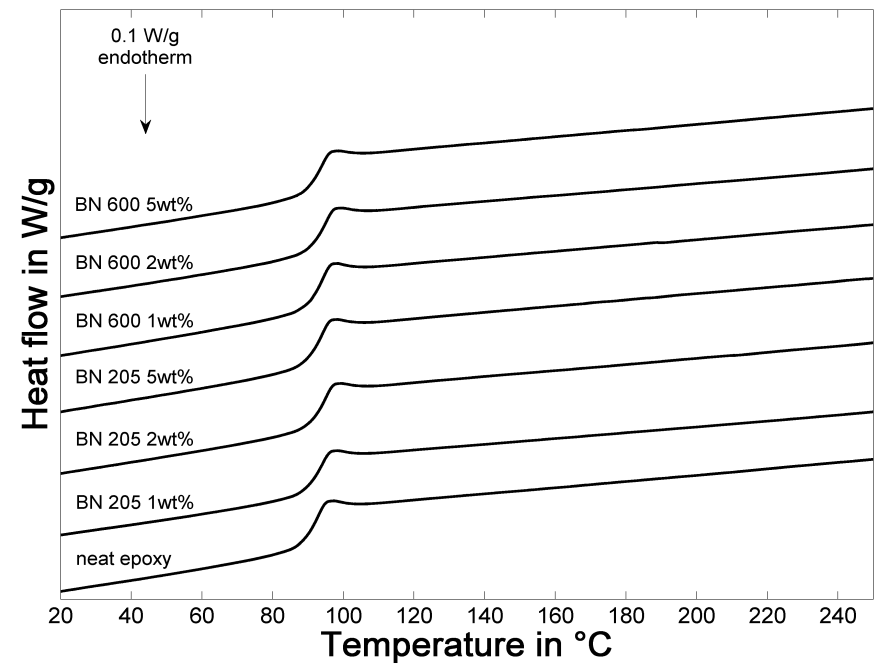

Figure 4. DSC graphs from the second thermal cycle for neat epoxy and the BN composites.

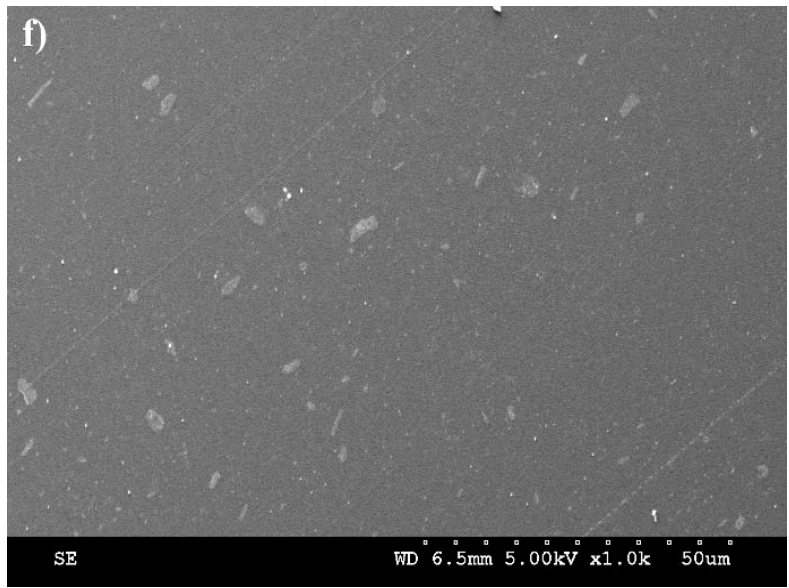

Table 2. Glass transition temperatures of neat epoxy and the BN composites.

\begin{tabular}{c|c}
\hline Sample type & $\mathrm{T}_{\mathrm{g}}$ in ${ }^{\circ} \mathrm{C}$ \\
\hline Neat epoxy & 93 \\
BN205 1wt\% & 94 \\
BN205 2wt\% & 94 \\
BN205 5wt\% & 96 \\
BN600 1wt\% & 94 \\
BN600 2wt\% & 94 \\
BN600 5wt\% & 95 \\
\hline
\end{tabular}

\subsection{DIELECTRIC SPECTROSCOPY}

Dielectric responses of the test specimens have been taken at excitation voltages of 3 and $500 \mathrm{~V}$ (see section 3.3), leading to low field strengths of close to $11 \mathrm{~V} / \mathrm{mm}$, or high field strengths of approximately $1.8 \mathrm{kV} / \mathrm{mm}$. Measurements at low and high excitation voltages were found to be quite similar for the respective sample types.

The dielectric spectroscopy experiments, both at low and high excitation voltages, have revealed $\alpha$ - and $\beta$-relaxation peaks for all test specimens (see Figure 5). In amorphous polymers those relaxation peaks can be related to relaxation processes of the main chains of the cross-linked epoxy chains due to the glass transition process in the case of $\alpha$-relaxation, or secondary relaxation processes due to movement of local groups attached to the main chain, as in the case of the $\beta$-relaxation. An additional phenomenon has been observed at high temperatures and low frequencies for neat epoxy and all BN composites likewise, the so-called electrode polarization (EP). This is a parasitic phenomenon well known for epoxy resin and its composites [12-14], which can be related to a delay in charge transfer at interfaces between sample and electrodes, giving rise to additional interfacial polarization on a macroscopic level. This peak due to EP at high temperatures and low frequencies is overshadowed by low-frequency dispersion due to charge fluctuation, possibly superimposed by electronic conductivity, which is a rather common behavior for solid insulating materials at elevated temperatures. 


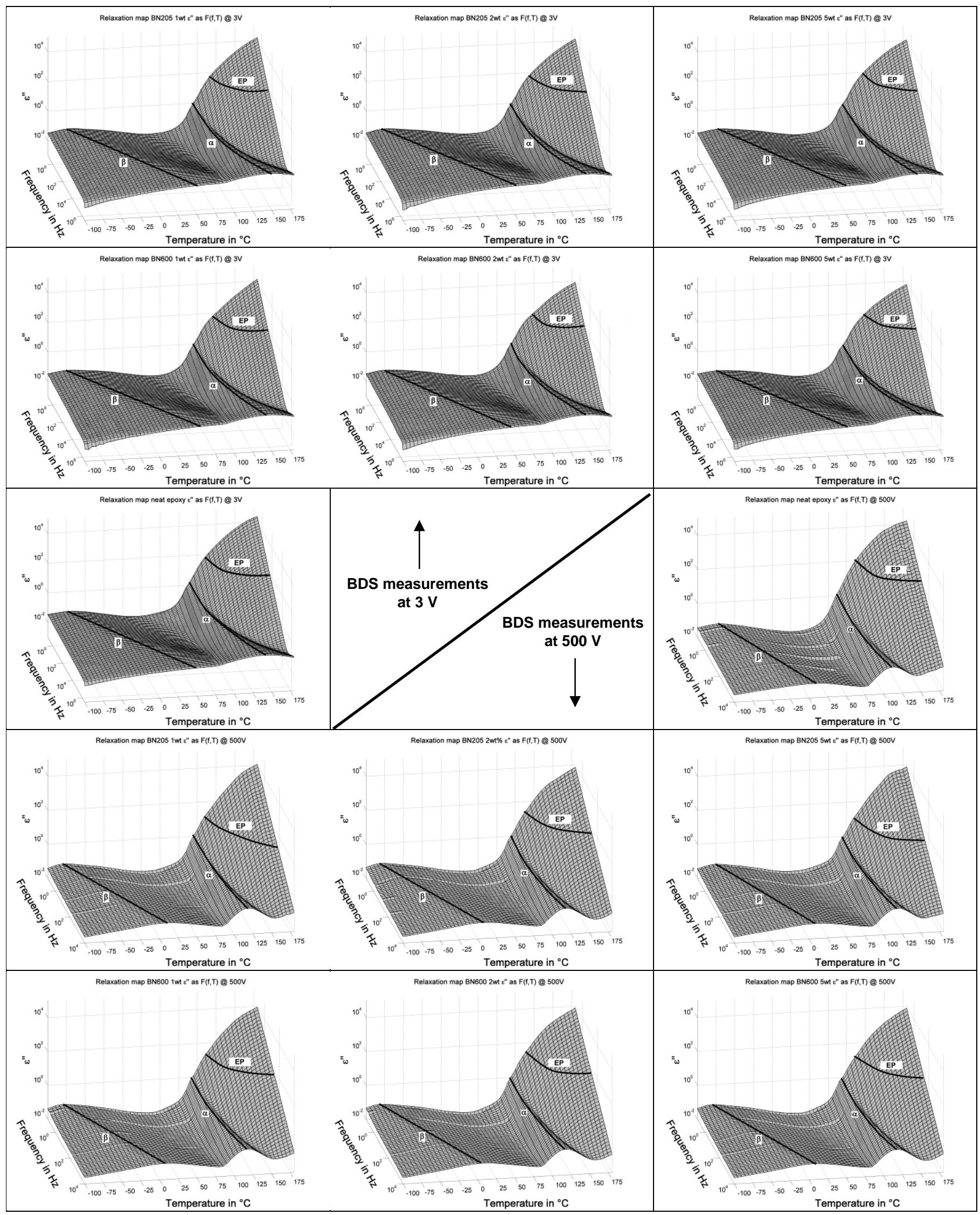

Figure 5. 3D plots of dielectric losses for all samples measured at either 3 or $500 \mathrm{~V}$, showing the main relaxation phenomena. BN composites revealed lower dielectric losses at high temperatures and low frequencies with increasing filler loadings. Electrode polarization (EP) due to a delay in charge transport at electrode-composite interfaces could additionally be detected for all samples 
Lower losses due to conductivity for the BN composites, as compared to neat epoxy, lead to more prominent peaks due to electrode polarization (EP) for the composites (Figure 5).

The dielectric responses measured at $20^{\circ} \mathrm{C}$ have shown a rather similar $\varepsilon^{\prime}$ for all samples (see Figure $6 \mathrm{a}$ ), whereas for $\varepsilon^{\prime \prime}$ a slight increase in dielectric losses could be detected (see Figure 6b). This is possibly due to the appearance of a lowmagnitude interfacial loss peak in the mid-frequency range, leading to a local conduction phenomenon. The additional loss peak is overshadowed by the low frequency wing of the $\beta$-relaxation peak, causing a slight shift of the $\beta$-peaks for the $\mathrm{BN}$ composites towards lower frequencies, as compared to neat epoxy, for which the $\beta$-peak was located in the vicinity of $10^{5} \mathrm{~Hz}$. Dielectric responses for all BN composites were found to be quite similar, like it has been discussed in [15], as a consequence of which the further discussion will be based on neat epoxy and the BN205 5wt\% composite (see Figure 7 and Figure 8).

Analogous to the observations made at $20^{\circ} \mathrm{C}$, introduction of BN particles in the epoxy matrix did not lead to significant changes of $\varepsilon^{\prime}$ for the composites as compared to neat epoxy, for temperatures of $60^{\circ} \mathrm{C}$ and below (see Figure 7a and Figure 8a). However, considering the temperatures above $60{ }^{\circ} \mathrm{C}$, a reduced $\varepsilon^{\prime}$ for the $\mathrm{BN}$ composites was found over the complete frequency range, getting more and more significant towards lower frequencies.
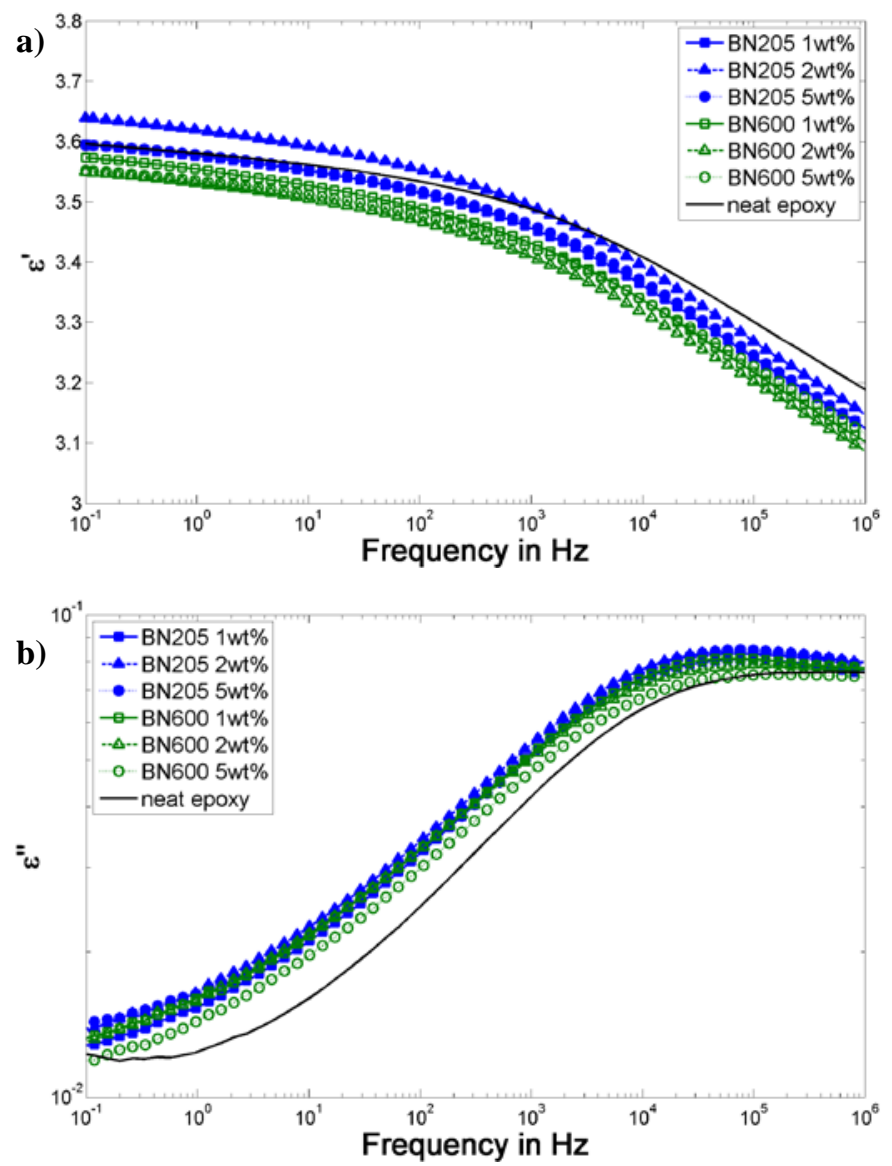

Figure 6. Dielectric response of neat epoxy and BN composites measured at 3 $\mathrm{V}$ and $20^{\circ} \mathrm{C}$; a) real part and b) imaginary part of the complex permittivity

Additionally the step in $\varepsilon^{\prime}$ at $100^{\circ} \mathrm{C}$ representing the $\alpha$-relaxation step, which was located around $100 \mathrm{~Hz}$ for neat epoxy, was found to be shifted about one order of magnitude towards lower frequencies for BN composites.

Evaluating $\varepsilon^{\prime \prime}$ of neat epoxy (Figure 7b) and BN205 5wt\% (Figure 8b), the BN composites were found to have marginally increased dielectric losses, for temperatures between $20^{\circ} \mathrm{C}$ and $60^{\circ} \mathrm{C}$, over the complete frequency range. This increase of dielectric losses supposedly originates in the abovementioned appearance of a low-magnitude interfacial loss peak in the mid-frequency range due to introduction of $\mathrm{BN}$ particles in the epoxy matrix (as it has been presented above for the results at $20^{\circ} \mathrm{C}$ in Figure 6b). Nevertheless, exceeding $60{ }^{\circ} \mathrm{C}$, the incorporation of $\mathrm{BN}$ filler in the organic matrix was found to significantly decrease dielectric losses of BN composites (Figure 8b) compared to neat epoxy (Figure 7b), especially for power frequencies and below. The $\alpha$-relaxation peak found around $100 \mathrm{~Hz}$ for neat epoxy at $100{ }^{\circ} \mathrm{C}$, was shifted about one order of magnitude towards lower frequencies for BN205 5wt\%. In contrast to the BN composites, neat epoxy showed a precursor of the $\alpha$-relaxation peak at $90{ }^{\circ} \mathrm{C}$ in the vicinity of $10 \mathrm{~Hz}$. This phenomenon, along with the findings of higher dielectric losses due to conductivity at elevated temperatures and low frequencies for the neat epoxy, as well as the shift of the $\alpha$-peak towards lower frequencies for the $\mathrm{BN}$ composites, can partially be explained by higher chain mobility in the neat epoxy as compared to the BN composites. It is further known, that free ionic species remaining from the synthesis process contribute to the increased dielectric losses in epoxy resins at high temperatures [13, 16-18]. Introducing $\mathrm{BN}$ particles in the epoxy matrix subsequently results in less mobile ionic charge carriers in the composite, leading to lower losses due to conductivity with increasing BN filler amount.

Lastly the quotient of $\varepsilon^{\prime \prime}$ and $\varepsilon^{\prime}$, the loss tangent or tan $\delta$, which is of interest in high voltage insulation engineering since it is often related to engineering requirements, is shown in the third column of Figure 8. Analogous to the aforementioned results, significantly lower values for the loss tangent of BN composites (Figure 8c) have been found at temperatures above $60^{\circ} \mathrm{C}$, compared to neat epoxy (Figure 7c). To give an example, for power frequencies at $80^{\circ} \mathrm{C}$, neat epoxy had a loss tangent of almost two times the one for BN205 $5 \mathrm{wt} \%$, whereas at $60{ }^{\circ} \mathrm{C}$ and below the loss tangent of neat epoxy was between 10 to $20 \%$ lower than for the BN composites.

\subsection{AC BREAKDOWN STRENGTH}

The retrieved AC breakdown (BD) data were treated by two parameter Weibull distribution according to IEEE 930 standard [19] to assess the breakdown strength of the tested specimens. The relevant parameters are the scale parameter $\alpha$, representing the dielectric breakdown strength in $\mathrm{kV} / \mathrm{mm}$ at the cumulative failure probability $(62.3 \%)$, as well as the shape parameter $\beta$, which is an inverse measurement for the scatter of BD data, thus higher values mean less scattering. The Weibull plots for the experimental data are displayed in 
Figure 9

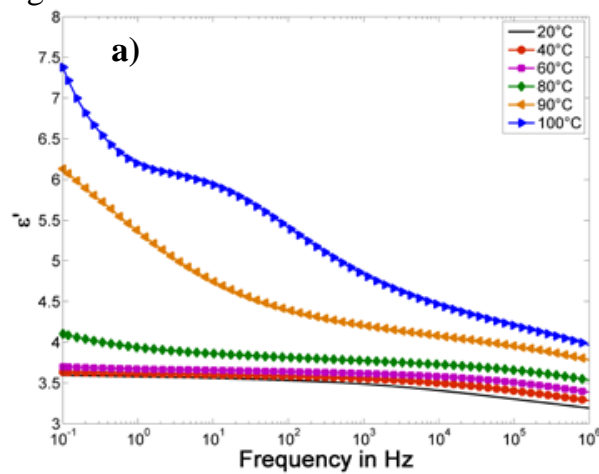

and

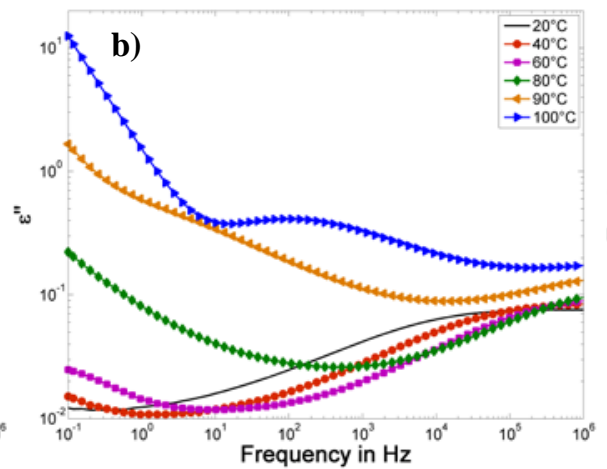

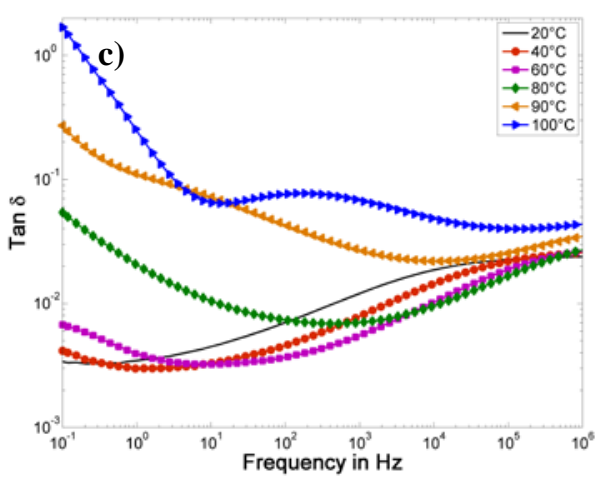

Figure 7. Neat epoxy temperature dependent real part (a), imaginary part (b) of complex permittivity and (c) loss tangent.
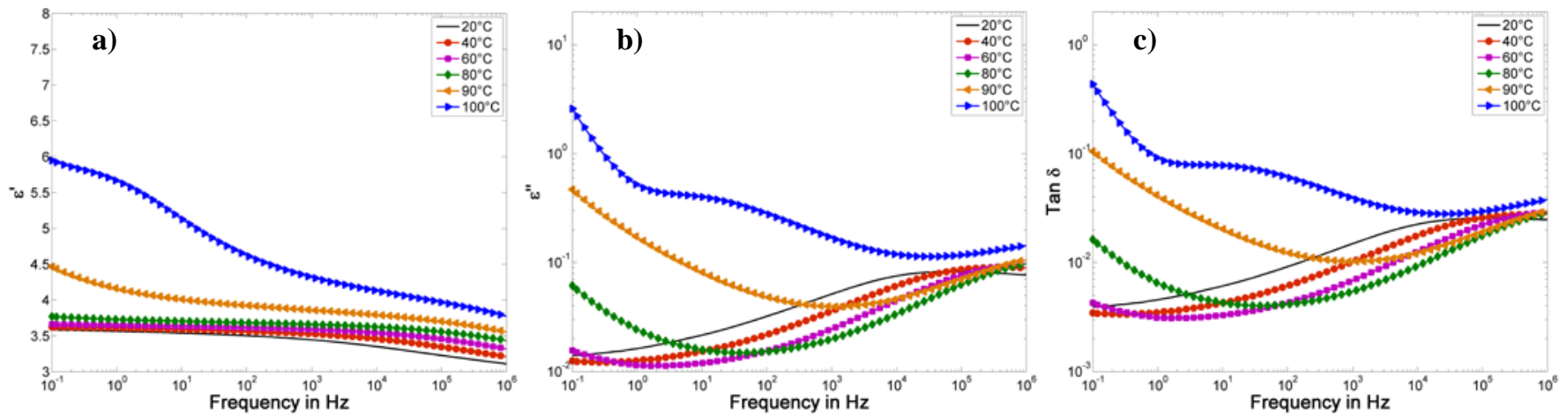

Figure 8. BN205 5wt\% temperature dependent real part (a), imaginary part (b) of complex permittivity and (c) loss tangent.

the corresponding Weibull parameters are summarized in Table 3. It has been found that the introduction of either submicrometric (BN205) or micrometric (BN600) boron nitride particles in the epoxy matrix resulted in decreased breakdown strengths of the composites compared to neat epoxy, even more so with increasing amount of filler. Thus for both filler types the $1 \mathrm{wt} \%$ composites had the least deterioration of dielectric BD strength, at values of approximately $140 \mathrm{kV} / \mathrm{mm}$. For the submicrometric composite BN205 2wt\%, addition of BN did not result in a significant reduction of BD strength though, as compared to the micrometric BN600 2wt\%.

It has repeatedly been reported in the literature, that incorporation of micrometric filler particles in epoxy resins resulted in diminishment of BD strength compared to the neat epoxy resins [5, 20-23]. This effect can be associated with locally enhanced electric field strengths in proximity of those filler particles, due to the mismatch of permittivity as well as orientation and shape of those particles, giving rise to electrical discharges.

Table 3. Weibull parameters obtained from Figure 9.

\begin{tabular}{c|c|c|c}
\hline Sample type & $\alpha$ & $\beta$ & $\begin{array}{c}\text { Avg. sample } \\
\text { thickness } \\
\text { in mm }\end{array}$ \\
\hline Neat epoxy & 160.4 & 19.62 & 0.233 \\
BN205 1wt\% & 141.8 & 20.63 & 0.217 \\
BN205 2wt\% & 140.2 & 23.69 & 0.223 \\
BN205 5wt\% & 133.5 & 16.03 & 0.209 \\
BN600 1wt\% & 143.7 & 17.80 & 0.208 \\
BN600 2wt\% & 133.2 & 19.71 & 0.223 \\
BN600 5wt\% & 131.9 & 18.26 & 0.216 \\
\hline
\end{tabular}

Additionally, despite all the care taken during sample preparation, defects (voids) are likely to be introduced in the epoxy matrix by micrometric particles during the compounding process [20, 23, 24]. Those defects, present at the filler surface, will cause additional field enhancement. The combination of abovementioned effects will subsequently lead to earlier $\mathrm{BD}$ of the composites at lower $\mathrm{BD}$ strengths as the neat polymer.

Bearing in mind these observations, along with the rather close values for BN205 1wt\% and BN205 2wt\%, it seems that submicrometric composites suffer less from diminished $\mathrm{BD}$ strengths as micrometric composites, at least as long as a good dispersion of the particles can be achieved. For BN205 5wt\% agglomerates with sizes close to the one of BN600 particles were found during SEM observation (see Figure 3), explaining the similar results for the two types of composites containing $5 \mathrm{wt} \%$ of either filler type.

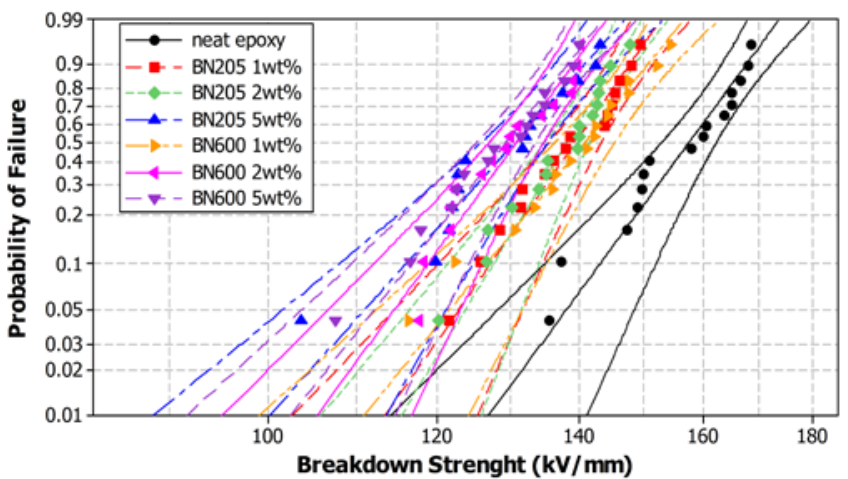

Figure 9. Weibull plots of breakdown strengths with $95 \%$ confidence intervals. 


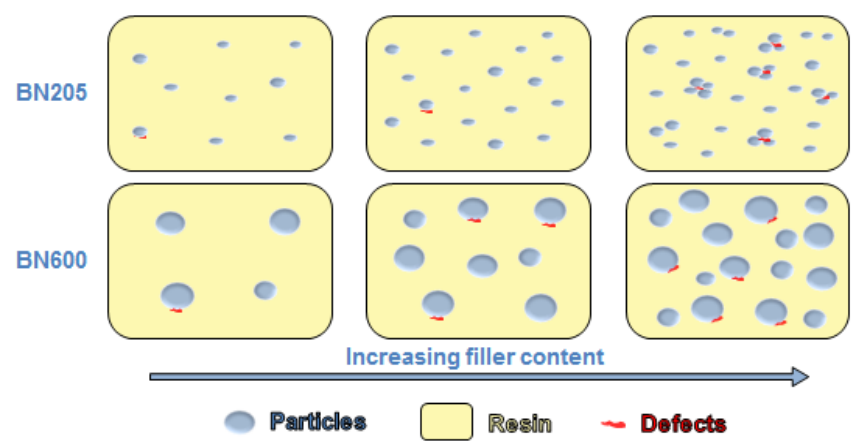

Figure 10. Schematic evolution of the microstructure in epoxy resin with increasing filler and subsequently defect contents.

In Figure 10 the evolution of the composites' microstructures depending on filler content and consequentially introduced defects is depicted, to better illustrate the effects of incorporating filler particles in a polymeric matrix along with their dispersion within it.

\subsection{RESISTANCE TO SURFACE DISCHAGE}

The results of the surface erosion experiment based on the eroded sample volumes are presented in Figure 11. It has been discovered that incorporation of low contents of BN particles in the epoxy resin has significantly improved the composites' resistances to electrical discharges by up to $50 \%$ less eroded volume, as in the case of BN600 1wt\%. The resistance to electrical discharges however diminished marginally with increase in filler content, a trend similar to BD strength.

Considering that polymeric composites with inorganic fillers are mainly eroded in the organic phase, hence in the polymeric region, one would expect to have less eroded volume on composites with higher contents of inorganic filler particles, as it has been reported in [21] for instance. The sole change of morphology due to incorporation of inorganic filler, along with the "shielding" effect of such inorganic particles cannot explain that deviating behavior for low and high filler contents. It is more likely that, at low filler contents, the introduction of defects in the matrix along with the micrometric particles, as well as electric field enhancement due to the mismatch of permittivity, give rise

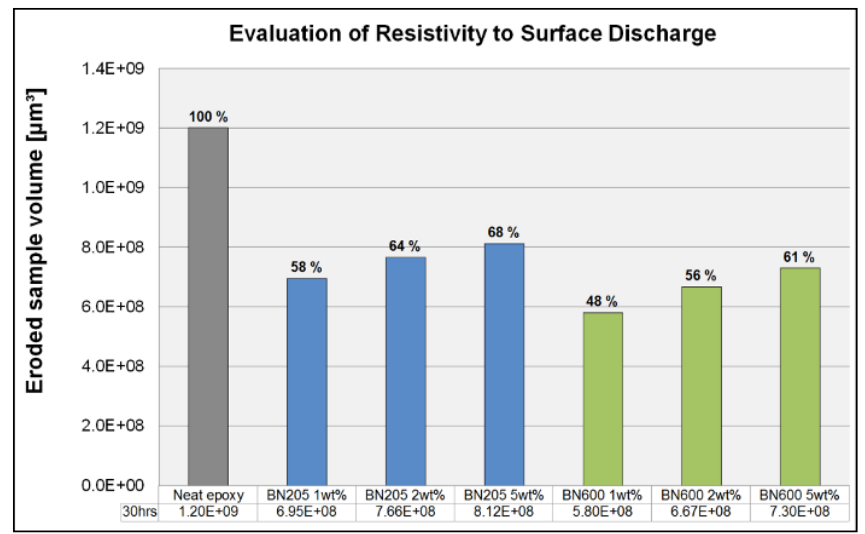

Figure 11. Comparison of eroded sample volume after exposure to partial discharges for 30 hours at $4 \mathrm{kV}_{\mathrm{RMS}}$ and $300 \mathrm{~Hz}$ to the slight deterioration of resistance to electrical discharge with increased BN contents.

Additionally, it has been found in our study that the micrometric BN600 composites had an overall better performance than their submicrometric BN205 counterparts. This is assumed to be due to the considerably larger specific surface area of the BN600 particles, which is approximately two times higher than for BN205 (see Table 1). Thus a larger protective or "shielding" area is provided by the same amount of BN600 in comparison to the BN205 particles when incorporated in the polymeric matrix.

\subsection{THERMAL CONDUCTIVITY}

Thermal conductivities of all composite types have been measured twice and the further discussion of thermal conductivities is based on the average value taken from the two measurement series. Based on the results presented in Figure 12 it has been found that incorporation of very low BN particle contents of $1 \mathrm{wt} \%$ and $2 \mathrm{wt} \%$ did not lead to a significant increase of thermal conductivity compared to the neat epoxy resin. Only marginally improved thermal conductivities by up to $5 \%$ have been found for those composites, contrary to the composites featuring $5 \mathrm{wt} \%$ of BN particles. For the submicrometric BN205 5wt\% composite a noteworthy increase of $17 \%$ in thermal conductivity has been attained, in contrast to $11 \%$ increased thermal conductivity for the micrometric BN600 5wt\% specimen.

It is commonly known that thermal conduction in solid materials is based on phonons (lattice vibrations) [25-27]. In amorphous materials, i.e. epoxy resins, phonon scattering is the dominating process, which occurs at either particleparticle, particle-matrix (equally at defects or pores), as well as interfaces of the amorphous structure in epoxy resin itself [25]. Phonon scattering causes diminishment of thermal conductivity within a material.

Introduction of high thermally conductive filler particles, i.e. BN, into the amorphous epoxy resin will consequently

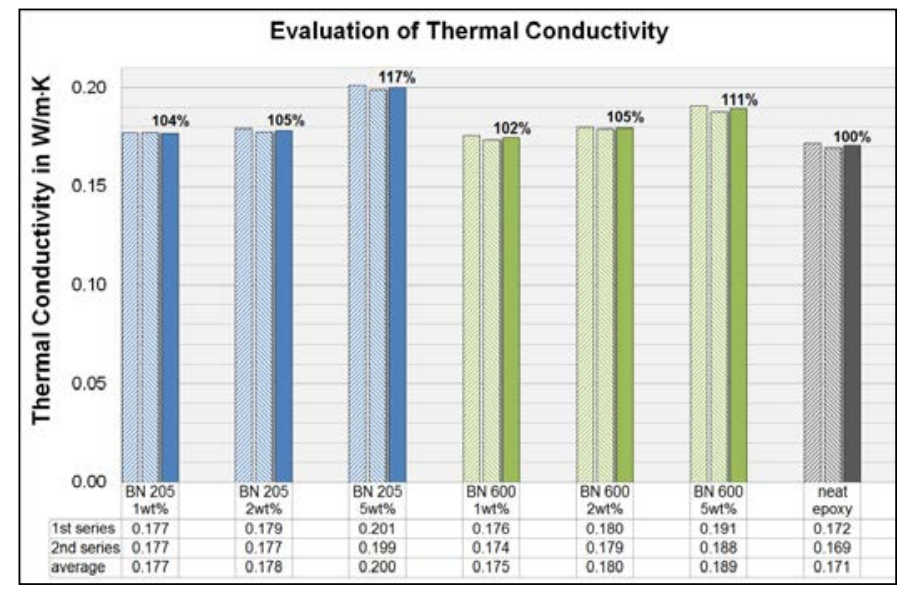

Figure 12. Comparison of thermal conductivities. Two measurements were taken on each sample type. The comparison of thermal conductivity was based on the average value for each.

result in local zones with good thermal conductivity, on a 
microscopic level. Thus, an improvement of the resulting composite's thermal conductivity with increasing content of $\mathrm{BN}$ particles can be expected, as the BN takes up more and more volume.

However, increasing the filler content in a composite multiplies the number of interfaces, in particular those between filler and the matrix, as well as particle to particle interfaces in case of agglomerations. Both phenomena can limit the amelioration of thermal conductivity. Subsequently phonon scattering becomes more and more important with rising $\mathrm{BN}$ particle content.

Comparing the thermal conductivities of BN205 5wt $\%$ and BN600 5wt\%, viz. 0.2 and $0.189 \mathrm{~W} / \mathrm{m} \cdot \mathrm{K}$, it is evident, that the submicrometric $\mathrm{BN}$ composite exhibits better thermal conductivity compared to the micrometric one. Two main factors will cause this behavior: firstly, the volume factor and secondly, the specific surface area. While BN205 has a density of $0.2 \mathrm{~g} / \mathrm{cm}^{3}$ in contrary to $0.5 \mathrm{~g} / \mathrm{cm}^{3}$ for BN600 (see Table 1), the submicrometric BN205 occupies 2.5 times more volume than the micrometric BN600, when introduced in equal wt\% into the epoxy matrix. In the same time, the surface area of BN600 particles is approximately two times larger than the BN205 particles' (as depicted in Table 1), which will result in more prominent phonon scattering at the particle-matrix interfaces within the BN600 composites, thus rendering their thermal conductivity lower in comparison to BN205 composites.

\section{CONCLUSIONS}

In this study, epoxy composites with rather low contents of submicrometric and micrometric boron nitride particles have been fabricated and analyzed in regards to their respective effects on morphology, as well as the dielectric and thermal performance.

It has been shown that incorporation of $\mathrm{BN}$ resulted in marginally increased glass transition temperatures for the $5 \mathrm{wt} \%$ composites.

Significantly lower dielectric losses resulted for $\mathrm{BN}$ composites at temperatures above $60{ }^{\circ} \mathrm{C}$, getting more and more pronounced with higher $\mathrm{BN}$ loadings.

The AC breakdown strength of $\mathrm{BN}$ composites was found to be diminished with increasing content of $\mathrm{BN}$ particles, although the deterioration of breakdown strength for submicrometric BN205 composites was found to be less distinct as compared to their micrometric BN counterparts, as micrometric $\mathrm{BN}$ particles are more likely to introduce defects in the epoxy matrix during the fabrication process.

Resistance to erosion due to electrical discharge has been remarkably increased by up to 50 \% less eroded volume for the BN composites. Composites with only $1 \mathrm{wt} \% \mathrm{BN}$ content were found to have the best erosion resistance due to less introduced defects in the epoxy matrix with less filler particles. The micrometric BN600 composites performed better than the submicrometric BN205 ones, which was attributed to the larger specific surface area of
BN600 (see Table 1), offering better protection against the electrical discharges.

The thermal conductivity of composites after addition of less than $5 \mathrm{wt} \% \mathrm{BN}$ didn't show any significant increase. The submicrometric BN205 5wt\% composite revealed a noteworthy increase of $17 \%$ in thermal conductivity compared to neat epoxy, the micrometric BN600 5wt\% composite however an increase of $11 \%$. The superior performance of the submicrometric BN composite over the micrometric one could be attributed to the larger volume fraction in the composites for submicrometric BN particles, as well as augmented phonon scattering at particle-matrix interfaces for the micrometric BN particles with a larger specific surface area.

To conclude, it has been shown in this study that incorporation of very low weight fractions of BN particles in an epoxy resin could result in noticeable improvements of dielectric and thermal performance of the resulting composites. Although the composites with a loading of $5 \mathrm{wt} \% \mathrm{BN}$ revealed deterioration in AC breakdown strength, it should be mentioned that the respective breakdown strengths of more than $130 \mathrm{kV} / \mathrm{mm}$ are still significantly higher than common electric stresses in high voltage insulation systems (e.g. 2 to $3 \mathrm{kV} / \mathrm{mm}$ in stator bars for rotating machines). Therefore the improvements in erosion resistance and thermal conductivity should be granted a higher emphasis.

\section{ACKNOWLEDGMENT}

The authors want to thank Prof. Alun Vaughan of the University of Southampton as well as Prof. Paul Lewin of the Tony Davies High Voltage Laboratory along with their teams, for the kind opportunity to produce our first set of epoxy samples there, as well as the much appreciated formation on how to do so. Hydro-Québec and the Natural Sciences and Engineering Research Council of Canada (NSERC) are gratefully recognized for their financial support.

\section{REFERENCES}

[1] R. Haubner, M. Wilhelm, R. Weissenbacher, and B. Lux, "Boron Nitrides-Properties, Synthesis and Applications," in High Performance Non-Oxide Ceramics II, Vol. 102, M. Jansen, Ed., ed: Springer Berlin / Heidelberg, 2002, pp. 1-45.

[2] A. Pakdel, C. Zhi, Y. Bando, and D. Golberg, "Low-dimensional boron nitride nanomaterials," Materials Today, Vol. 15, pp. 256-265, 2012.

[3] R. Kochetov, T. Andritsch, U. Lafont, P. H. F. Morshuis, S. J. Picken, and J. J. Smit, "Thermal behaviour of epoxy resin filled with high thermal conductivity nanopowders," IEEE Electr. Insul. Conf., 2009, pp. 524-528, 2009.

[4] R. Kochetov, T. Andritsch, P. H. F. Morshuis, and J. J. Smit, "Effect of filler size on complex permittivity and thermal conductivity of epoxy-based composites filled with BN particles," IEEE Conf. Electr. Insul. Dielectr. Phenomena (CEIDP), pp. 1-4, 2010.

[5] W. Zengbin, T. Iizuka, M. Kozako, Y. Ohki, and T. Tanaka, "Development of epoxy/BN composites with high thermal conductivity and sufficient dielectric breakdown strength part IIbreakdown strength," IEEE Trans. Dielectr. Electr. Insul., Vol. 18, pp. 1973-1983, 2011. 
[6] W. Zengbin, T. Iizuka, M. Kozako, Y. Ohki, and T. Tanaka, "Development of epoxy/BN composites with high thermal conductivity and sufficient dielectric breakdown strength part I sample preparations and thermal conductivity," IEEE Trans. Dielectr. Electr. Insul., Vol. 18, pp. 1963-1972, 2011.

[7] M. Reading, A. S. Vaughan, and P. L. Lewin, "An investigation into improving the breakdown strength and thermal conduction of an epoxy system using boron nitride," IEEE Conf. Electr. Insul. Dielectr. Phenomena (CEIDP), pp. 636-639, 2011.

[8] T. Tanaka, W. Zengbin, T. Iizuka, M. Kozako, and Y. Ohki, "High thermal conductivity epoxy/BN composites with sufficient dielectric breakdown strength," Int'l. Conf. Power Energy Syst. (ICPS), pp. 14, 2011.

[9] T. Andritsch, R. Kochetov, Y. T. Gebrekiros, P. H. F. Morshuis, and J. J. Smit, "Short term DC breakdown strength in epoxy based BN nano- and microcomposites," IEEE Int'l. Conf. Solid Dielectr. (ICSD), pp. 1-4, 2010.

[10] ASTM-International, "ASTM D149 - 09: Standard Test Method for Dielectric Breakdown Voltage and Dielectric Strength of Solid Electrical Insulating Materials at Commercial Power Frequencies," ed. West Conshohocken, PA, 2013.

[11] ASTM-International, "ASTM E1530 - 11: Standard Test Method for Evaluating the Resistance to Thermal Transmission of Materials by the Guarded Heat Flow Meter Technique," ed, 2011.

[12] I. Preda, J. Castellon, S. Agnel, H. Couderc, M. Frechette, F. Gao, R. Nigmatullin, S. Thompson and A.F. Vaessen, "Dielectric response of various partially cured epoxy nanocomposites," IEEE Trans. Dielectr. Electr. Insul., Vol. 20, pp. 580-591, 2013.

[13] F. Tian and Y. Ohki, "Charge transport and electrode polarization in epoxy resin at high temperatures," J. phys. D, Appl. Phys., Vol. 47, p. 045311, 2014.

[14] P.B. Ishai, E. Levy, Y. Feldman, M.S. Talary and A. Caduff, "Electrode polarization in dielectric measurements: A review," Meas. Sci. Technol., Vol. 24, 2013.

[15] T. F. Heid, N. Freebody, M. F. Fréchette, H. Couderc, C. Vanga, E. David and A.S. Vaughan, "Dielectric properties of epoxy/BN microand meso-composites: Dielectric response at low and high electrical field strengths," IEEE Electr. Insul. Conf. (EIC), pp. 25-29, 2013.

[16] J. Ulański, K. Friedrich, G. Boiteux, and G. Seytre, "Evolution of ion mobility in cured epoxy-amine system as determined by time-offlight method," J. Appl. Polymer Sci., Vol. 65, pp. 1143-1150, 1997.

[17] K. Friedrich, J. Ulanski, G. Boiteux, and G. Seytre, "Time-of-flight ion mobility measurements in epoxy-amine systems during curing," IEEE Trans. Dielectr. Electr. Insul., Vol. 8, pp. 572-576, 2001.

[18] J. Katayama, Y. Ohki, N. Fuse, M. Kozako, and T. Tanaka, "Effects of nanofiller materials on the dielectric properties of epoxy nanocomposites," IEEE Trans. Dielectr. Electr. Insul., Vol. 20, pp. 157-165, 2013.

[19] "IEEE Std 930-2004: IEEE Guide for the Statistical Analysis of Electrical Insulation Breakdown Data," ed. New York, NY: IEEE, 2004.

[20] R. Lovell, "The Effect of Specimen Size on the Electric Breakdown of Unfilled and Filled Epoxy Polymers," IEEE Trans. Electr. Insul., Vol. 11, pp. 110-114, 1976.

[21] Z. Li, K. Okamoto, Y. Ohki, and T. Tanaka, "The role of nano and micro particles on partial discharge and breakdown strength in epoxy composites," IEEE Trans. Dielectr. Electr. Insul., Vol. 18, pp. 675681, 2011.

[22] Z. Li, K. Okamoto, Y. Ohki, and T. Tanaka, "Role of nano-filler on partial discharge resistance and dielectric breakdown strength of micro- $\mathrm{Al}_{2} \mathrm{O}_{3} /$ epoxy composites," IEEE 9th Int'l.l Conf. Properties and Applications of Dielectric Materials (ICPADM), pp. 753-756, 2009.

[23] Q. Wang, Z. Li, J. Wu, and Y. Yin, "The thermal conductivity and electrical strength of epoxy resin with different filler content of micro and nano alumina," IEEE Int'l. Conf. Condition Monitoring and Diagnosis (CMD), pp. 1110-1113, 2012.

[24] P. Preetha and M. J. Thomas, "AC breakdown characteristics of epoxy nanocomposites," IEEE Trans. Dielectr. Electr. Insul., Vol. 18, pp. 1526-1534, 2011.

[25] Y. Takezawa, M. Akatsuka, and C. Farren, "High thermal conductive epoxy resins with controlled high order structure," IEEE Int'l. Conf. Properties and Applications of Dielectric Materials (ICPADM), Vol. 3, pp. 1146-1149, 2003.
[26] W. Cui, F. Du, J. Zhao, W. Zhang, Y. Yang, X. Xie and Y. Mai, "Improving thermal conductivity while retaining high electrical resistivity of epoxy composites by incorporating silica-coated multiwalled carbon nanotubes," Carbon, Vol. 49, pp. 495-500, 2011.

[27] X. Huang, T. Iizuka, P. Jiang, Y. Ohki, and T. Tanaka, "Role of Interface on the Thermal Conductivity of Highly Filled Dielectric Epoxy/AlN Composites," J. Phys. Chem. C, Vol. 116, pp. 1362913639, 2012/06/28 2012.

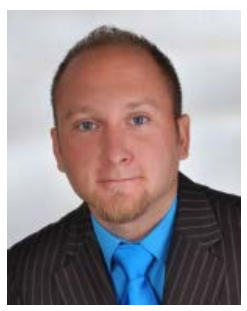

Thomas Heid (S'10) studied electrical engineering at Graz University of Technology (Austria) where he graduated with a M.Sc. (2011), specializing in high voltage engineering. He was a project assistant at the Institute of High Voltage Engineering and System Management and the Test Institute of High Voltage Engineering (Graz, Austria) till 2012, where he has been involved in numerical calculations for high voltage cable systems, life cycle analysis for stator bars, as well as high voltage testing of electrical equipment. Currently he is a Ph.D. student with the Hydro-Québec Research Institute (IREQ) in cooperation with the École de Technologie Supérieure (ETS). His main research interest is the development of nanodielectrics for application in high voltage insulation systems.

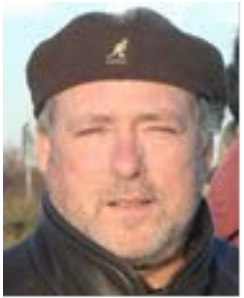

Dr. Michel Fréchette has a graduate degree in physics. He joined Hydro-Québec's Research Institute (IREQ) in the $20^{\text {th }}$ century. Since then, he has been involved in applied basic research in various fields related to electrical insulation and insulating materials. His major contributions involve discharge physics, dielectric phenomena and nanodielectrics.

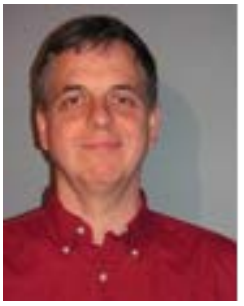

Eric David (M'03-SM'07) was born in Montreal in 1965. He has been a member of the IEEE since 2002. He received an M.Sc.A. and a Ph.D. degrees in engineering physics from the École Polytechnique de Montréal in 1989 and 1996, respectively. He joined the Hydro-Québec Research Institute (IREQ) in 1998, and from 2001 to 2002, where he was active in the field of dielectric materials used for underground cables and rotating machines. He is now a Professor at the Department of Mechanical Engineering in the École de Technologie Supérieure (ETS) in Montreal. His research interests include dielectric and nanodielectric materials, rotating machinery and underground cable insulation. He is an Associate Editor of the IEEE Transactions on Dielectrics and Electrical Insulation. 